\title{
ASSESSING UN INDICATORS OF LAND DEGRADATION NEUTRALITY AND PROPORTION OF DEGRADED LAND OVER BOTSWANA USING REMOTE SENSING BASED NATIONAL LEVEL METRICS
}

\author{
Short title: Land Degradation Neutrality assessment for Botswana
}

\author{
Felicia O. Akinyemi ${ }^{\mathrm{a}, \mathrm{b}^{*}}$, Gohar Ghazaryanc ${ }^{\mathrm{and}}$ Olena Dubovyk ${ }^{\mathrm{c}}$ \\ ${ }^{a}$ Geographies of Sustainability Department, Institute of Geography, University of Bern, Hallerstrasse \\ 12, 3012 Bern, Switzerland \\ ${ }^{b}$ Earth and Environmental Science, Botswana International University of Science and \\ Technology, Private Bag 16, Palapye, Botswana \\ ${ }^{b}$ Centre for Remote Sensing of Land Surfaces, University of Bonn, Genscherallee 3, \\ 53113 Bonn, Germany
}

\section{ABSTRACT}

Achieving land degradation neutrality (LDN) has been proposed to stem the loss of land resources globally. To date, LDN operationalization at country level has remained a challenge both from a policy and science perspective. Using an approach incorporating cloud-based geospatial computing with machine learning, national level datasets of land cover, land productivity dynamics, soil organic carbon stocks were developed using the example of Botswana. LDN and proportion of degraded land were assessed. Between 2000 and 2015, grassland lost 17\% of its original size, the highest level of loss for any land category; land productivity decline was highest in artificial surface

\footnotetext{
1 *Corresponding author. E-mail: felicia.akinyemi@gmail.com
}

This article has been accepted for publication and undergone full peer review but has not been through the copyediting, typesetting, pagination and proofreading process which may lead to differences between this version and the Version of Record. Please cite this article as doi: $10.1002 /$ ldr.3695 
areas (11\%), whereas 36\% of croplands show early signs of decline. With the use of national metrics (NM), areas under degradation were found to be $32.6 \%$ compared to $51.4 \%$ surface area when global default datasets (DD) are used. Estimates of degraded land computed with NM and DD were validated in Palapye, an agro-pastoral region in eastern Botswana, where Composite Land Degradation Index (CLDI) field-based data exists. Comparing land degradation (LD) in the three datasets (NM, DD, and CLDI), NM estimates were closest to the field data. The extra efforts put into developing national level data for LD assessment in this study is, thus, well-justified. Beyond demonstrating remote sensing viability for LD assessment, the study developed procedures for generating and validating national level datasets. Using these procedures, LD monitoring will be enhanced in Botswana and elsewhere since these remote sensing datasets can be updated using freely available satellite datasets.

KEYWORDS: land degradation neutrality, land cover, land productivity dynamics, soil organic carbon stocks, Google Earth Engine, Mann-Kendall

\section{INTRODUCTION}

Land degradation (LD) is a global challenge, as it affects all biomes (Nkonya, 2016; Sims et al., 2019). The negative effects on people’s livelihoods across all regions makes LD a major concern in achieving food security, reducing poverty, halting biodiversity loss, as exemplified by the Sustainable Development Goals (SDGs) and the various United Nations 
(UN) conventions, such as on combating desertification (UNCCD), on biological diversity (CBD), on climate change (UNFCCC). The combined effects of LD and climate change exacerbate the vulnerability of human and natural systems (Webb et al., 2017). Consequently, degrading natural resources diminishes people's ability, particularly the poor, to mitigate and adapt to the impacts of environmental change (Aynekulu et al., 2017).

High on the global development agenda is land degradation neutrality (LDN) and the corresponding SDG 15.3.1 that aims to estimate the proportion of degraded land over the total land area (UN, 2015). Aimed at halting, reversing LD and restoring degraded land, operationalizing LDN is difficult because LD is multidimensional and dynamic in nature (Sommer et al., 2011; Chasek et al., 2015). Harmonization of LDN constructs and methodologies is required to allow for LD estimates comparison among countries and to minimize complexity in interpretation (Gonzalez-Roglich et al., 2019). National LDN baseline must be set for the period 2000-2015 as reference for the subsequent monitoring of LD till 2030. The three LDN sub-indicators and their associated metrics are: i) land cover (LC) change - computed over the 15-year period for capturing LC trends - as a proxy for land use change, ii) land productivity dynamics (LPD) represented by trends in Net Primary Productivity (NPP), and iii) carbon stocks for trends in above and below ground carbon (UNCCD, 2016). LDN baseline is largely lacking in many countries but it is required for the SDG 15.3.1 monitoring. The UNCCD recommends using global datasets to estimate subindicators in the absence of reliable national estimates (Sims et al., 2019). Global datasets, 
although freely available, are not so well appropriate for LD policy action at the countrylevel because of their coarse resolution amongst other limitations.

The two objectives of this study are: i) to contribute to operationalizing LDN in drylands using the case of Botswana, and ii) to foster the estimation of LDN sub-indicators using national level datasets. Botswana has no confirmed estimate of the national extent of degraded lands as results from various studies vary considerably due to differences in methods and scales of assessment (Foster, 2006). Kayombo et al., (2005) put LD affected land in Botswana at 69\%. Using a three-point nominal scale (low, moderate, severe) to rate LD indicators, Sebego et al. (2019) found moderate to severe degradation in high utilization areas due to soil degradation and vegetation structure change in Boteti, north-central Botswana. Akinyemi et al. (2019) found that in Palapye, eastern Botswana, 24\% of land area is relatively stable, $3 \%$ show very low degradation, $35 \%$ show low degradation, whereas areas with medium, high, and very high degradation levels are $21 \%, 13 \%$, and $4 \%$ respectively. Akinyemi \& Kgomo (2019) found that drought and tree species richness and diversity explained about 50\% of the variance in vegetation degradation levels between 1998 and 2016 for the same region. Botswana's level of confidence in the reported LDN and proportion of degraded land estimates to the UNCCD is low due to the lack of national datasets and field verification (Government of Botswana — GoB, 2018).

This study produced national level estimates of the three LDN sub-indicators with satellite images of higher resolution than were used for developing the recommended global datasets. 
We used remote sensing-based time series for derivation of land productivity related indicators as well as machine learning algorithms for land cover classification. Remote sensing datasets have been shown to be a valuable tool for assessing long-term vegetation productivity and cover decline, analysis of factors driving LD and land cover status (Lanfredi et al., 2015; Dubovyk et al., 2017). Furthermore, the use of state-of-the-art machine learning algorithms allows for efficient image classification, which is an important input for LD assessment. These algorithms can model complex class signatures and accept a variety of input predictor data (Maxwell et al., 2018). To justify the additional efforts countries are putting into developing national level datasets, we compared and validated estimates produced using the recommended default global datasets (DD) and national metrics (NM) produced in this study. Our study goes beyond assessing LDN and SDG 15.3.1 to validating land degradation using field-based data for a case study in eastern Botswana. The obtained results would facilitate developing remote sensing-based national level metrics of land degradation for other dryland countries with sparse data.

\section{MATERIALS AND METHODS}

\subsection{Study Site}

Botswana is a landlocked country in southern Africa (Figure 1). With a semi-arid, hot steppe climate (Köppen’s BSh classification) and $475 \mathrm{~mm}$ average annual rainfall, Botswana is 
highly vulnerable to environmental change including LD. Sustainable natural resources use and combating LD are enshrined in Botswana’s Vision 2036 (GoB, 2016).

\author{
Insert Figure 1 here
}

\title{
2.2 Data
}

The three LDN sub-indicators and SDG 15.3.1 were computed using the recommended default datasets (DD) and the national metrics (NM) we developed (Table 1). For consistency, all maps use the coordinate reference system EPSG 4236 with WGS84 datum.

Insert Table 1 here

\subsubsection{Land cover}

Alongside the recommended 300m ESA-CCI LC (refer to Table 1 for details), LCs for 2015 and 2018 were produced in Google Earth Engine (GEE) based on Landsat 8 images (30m) and/or Sentinel-1. The GHG 2000 LC scheme (Level 1) uses these land categories, i.e. forestland (tree-covered areas) ${ }^{\mathrm{i}}$, grassland, cropland, wetland, settlement (artificial surfaces) and otherland. Forests in Botswana include woodlands and comprise multi-layered tree canopies with over $10 \%$ cover, minimum size of 0.5 ha, and heights of more than $5 \mathrm{~m}$ (Department of Forestry and Range Resources - DFRR, 2017). Grassland incorporated 
shrub and sparsely vegetated areas, whereas otherland comprised bareland, rock outcrops, and sand dunes (Akinyemi \& Mashame, 2018).

Confusion between bare soils, dry riverbeds, uncultivated croplands, and artificial surfaces represented by settlements necessitated post-processing of the LC maps using official and well-established external datasets. To verify the occurrence and extent of settlements and croplands in Botswana we used the GHS urban areas (Pesaresi et al., 2015), MESA-SADC cities data and GHG 2010 LC. We improved the GHS and GHG by editing areas misclassified as settlement and croplands with high resolution images such as in GEP. Waterbody data from the Botswana Department of Survey and Mapping was used to correct waterbody pixels. Classification accuracy improved from $74 \%$ to $85 \%$ by relabelling misclassified pixels.

\subsubsection{Land productivity dynamics}

According to Table 1, two sets of data were used in computing LPD in this study. The JRC (1km) global LPD dataset was used to compute the DD, whereas for the NM, MODIS NDVI 250m data (MOD13Q1-coll6) was used (see Table 1).

\subsubsection{Soil Organic Carbon Stocks}

Data used for computing soil organic carbon stocks (SOCs) as a proxy for above and below ground carbon stocks (in tonnes per hectare - $\mathrm{t} / \mathrm{ha}$ ) were derived from the SoilGrid250m at 
three depths $(0-5 \mathrm{~cm}, 5-15 \mathrm{~cm}, 15-30 \mathrm{~cm})$ (see Table 1$)$. These are bulk density of fine earth $\left(\mathrm{kg} / \mathrm{m}^{3}\right)$, coarse fragments (volumetric\%: $\mathrm{cm}^{3} / \mathrm{cm}^{3}$ ), and SOC content. As SoilGrids $250 \mathrm{~m}$ has input legacy soil records spanning several decades, it is recommended for use in the baseline year for computing SOCs in the absence of better national carbon stock databases (Hengl et al., 2017; Gichenje \& Godinho, 2018; UNCCD, 2018).

\subsubsection{Auxiliary data}

We used reference data collected from the field and from higher resolution images in GEP to train and validate the 2015 and 2018 maps. Tier 3 CLDI field-based data for Palapye with five LD classes was used to validate the estimated proportion of degraded land. CLDI incorporates physical, chemical, and biological degradation indicators in its LD assessment. An extensive description of the CLDI datasets and procedure is given in Akinyemi et al. (2019).

\subsection{Methods}

LDN sub-indicator (LC, LPD, and SOCs) national datasets were created from satellite images using cloud-based geospatial computing coupled with machine learning algorithms (see the workflow in Figure 2).

Insert Figure 2 here 


\subsubsection{Sub-indicator 1: Land cover change and degradation}

LC degradation is one of the three parameters required to compute the SDG 15.3.1 (i.e. the amount of degraded land as a proportion of the total land area). The non-parametric Random Forest (RF) machine learning algorithm in GEE was used to produce the 2015 and 2018 LC maps. RF as an ensemble method was selected as it outperforms other methods and has been shown to result in higher accuracy for classification (Maxwell et al., 2018). The input features for the 2018 classification were the red, NIR and SWIR bands and Normalized Difference Moisture Index from Landsat (30m) composites for the dry season along with Sentinel-1 VV (Vertical transmit—Vertical receive) and VH (Vertical transmit—Horizontal receive) mean. To classify LC in 2015, Landsat 8 (30m) composites for the dry and wet seasons were combined to minimize class confusion between waterbodies, baresoils, croplands and artificial surfaces. The confusion between these categories arose as year 2015 was an exceptionally dry year due to severe drought (Akinyemi, 2017). Training and validation data for the 2015 image classification were generated based on the 2018 map by stratified sampling using 50 points per category. To minimize within class spectral heterogeneity, the training data for 2015 were filtered based on temporal profiles of NDVI and the samples with the highest deviation were excluded. The number of trees in the ensemble for both years was 300 and the number of nodes per split was equal to the square root of the number of input features (Ghazaryan et al., 2018). Similar method was described by Hao et al. (2016) and 
Xie et al. (2019), whereby training data were automatically generated using input satellite images and existing land cover products.

To assess degradation, LC transitions between 2000 and 2015 were analysed. That a land cover type transitioned to another type does not explicitly indicate that land is degraded. To infer degradation, LC transitions are interpreted according to the LD processes occurring in the study context considering the development goals (Sims et al., 2019). For this study, we refined the UNCCD typologies of degrading LC changes (Sims et al., 2019) based on our first-hand knowledge of local LD processes (Akinyemi et al., 2019). We also relied on information provided in the Botswana report to the UNCCD (Government of Botswana, 2018). The typology detailing the correspondence between LC transitions and land degradation categories is described in subsections 3.1 "Land cover transitions and degradation”. Using this context-based knowledge, identified transitions are regarded as degraded when such transitions are undesirable. An example is deforestation such as when tree-covered areas transition into grasslands. Another undesirable transition is the loss of settlement areas such as to otherland. This is because the national development plan aims to provide decent and affordable housing for $90 \%$ of Botswana's population (Ministry of Finance and Development Planning - MFDP, 2016). Unchanged land covers are regarded as stable, whereas other transitions are regarded as improvements such as the conversion of otherlands into forests.

\subsubsection{Sub-indicator 2: Loss of land productivity}


LPD is measured to capture the above-ground vegetation productivity using the NPP as an indicator. NPP is the net amount of carbon assimilated after photosynthesis and autotrophic respiration over the study period (Clark et al., 2001). As NPP is time consuming to measure, NDVI is used as a proxy as it strongly correlates with NPP (Higginbottom \& Symeonakis, 2014; Dubovyk et al., 2016). Several studies have found that NDVI gives a credible assessment of temporal changes in vegetation and an indicator of LD, although it cannot be used to ascertain the degradation process (Dubovyk et al., 2015; Gichenje \& Godinho, 2018; Gonzalez-Roglich et al., 2019).

As an LDN indicator, LPD is measured in terms of the state, trend, and performance of vegetation productivity (Sim et al., 2019; Trends.Earth, 2019). State captures recent changes to vegetation productivity and is computed by comparing the initial biomass to the final biomass in the time series. The initial biomass is calculated as the mean of the time series of years 2000 to 2012 to better capture the likely range of variability. The final biomass is calculated as the mean of the last three years in the time series (2013-2015). These last three years are used to minimise annual fluctuations in vegetation productivity associated with climate (Trends.Earth, 2019). Trend analysis is conducted using the Mann-Kendall (MK) non-parametric test at the 95\% confidence level to determine the significance of changes in vegetation productivity over time (Sims et al., 2019). MK evaluates the occurrence of monotonic single directional trend (Tüshaus et al., 2014) and the tau $(\tau)$ coefficient ranges from -1 to +1 with values greater than 0 indicating a continually increasing (monotonic 
greening) trend, and values less than 0 indicating a continually decreasing (monotonic browning) trend (de Jong et al., 2011). Performance compares the local levels of productivity with that of similar areas in the country.

These three productivity indicators (trend, state, and performance) are combined into five qualitative LPD classes (Declining, Early sign of decline, Stable but stressed, Stable, Improving). A significant negative trend over the analysis period indicates productivity decline, whereas a significant positive trend indicates increase in vegetation cover and biomass, hence improvement. Land is potentially degraded if significant negative trend is found over time or where both State and Performance metrics indicate potential degradation, including areas without significant negative trend (Sims et al., 2019; Gonzalez-Roglich et al., 2019). LPD was computed in this study for both DD and NM. LPD for the NM was computed with MODIS NDVI (250m) dataset for estimating SDG 15.3.1. The resolution of the MODIS NDVI is higher than the $1 \mathrm{~km}$ JRC LPD used in computing LPD for the DD.

\subsubsection{Sub-indicator 3: Loss of soil organic carbon}

Carbon stocks, which include above and below ground biomass, are recommended, but there is a lack of quality data about carbon stocks in shrubs/woody plants, grasses, croplands, and others above and below ground (Sims et al., 2019). Since soils hold the largest amount of carbon, SOCs are used as a proxy for LD assessment (Raich \& Schlesinger, 1992; DuarteGuardia et al., 2019). In the absence of national data, SOCs for use in this study were 
computed approximately for the year 2000 (see UNCCD, 2018 for justification) following Hengl et al. (2017) as in equation 1.

SOC stock $[$ ton $/$ ha $]=\mathrm{SOC} / 1000 \times \mathrm{BLD} \times(1-\mathrm{CRF} / 100) \times \mathrm{HOT} / 100 \times 10 \ldots \ldots$.Eq. 1

Where SOC $=$ soil organic carbon content $(\%: \mathrm{g} / \mathrm{kg}), \mathrm{BLD}=$ bulk density of fine earth

$\left(\mathrm{kg} / \mathrm{m}^{3}\right), \mathrm{CRF}=$ coarse fragments $\left(\right.$ volumetric\%: $\left.\mathrm{cm}^{3} / \mathrm{cm}^{3}\right)$, HOT $=$ horizon thickness $/$ depth interval $(0-30 \mathrm{~cm})$. SOCs in 2015 were estimated for Botswana using the carbon conversion coefficients in relation to LC transitions for a tropical dry climate as implemented in the Trends.Earth QGIS plugin (Trends.Earth, 2019). Based on the change in SOCs calculated per pixel between 2000 and 2015, degradation in SOCs is defined as a loss greater than 10\% of the 2000 stock values (Sims et al., 2019).

\subsubsection{Land degradation}

SDG 15.3.1 is concerned with assessing the proportion of land that is degraded over the total land area. With LDN baseline set for the three sub-indicators (LC, land productivity, and SOCs) between 2000 and 2015, monitoring is to be conducted until 2030. In assessing and monitoring LDN, other site-specific indicators of LD that are relevant to a country can be incorporated, such as heavy metal contamination in soils if available (Elbehri et al., 2017). LDN is said to be achieved when there is an improvement in all three sub-indicators, or they remain unchanged. Otherwise, the unit of land is classified as degraded if any sub-indicator 
is degraded. This is referred to as the 'one out, all out' rule - 1OAO (UNCCD, 2018; Sims et al., 2019). We estimated the amount of degraded land according to the different LC types using tier 1 (default data—DD) and tier 2 (national metrics—NM) datasets (see Table 1). We afterward examined whether the NMs we developed improved estimates of the amount of degraded land. Furthermore, we validated both the DD and NM using field-based, tier 3 data for Palapye. Palapye, the validation site (refer to Figure 1), is an agro-pastoral region in eastern Botswana. It was chosen because systematic studies were conducted there on climate change and variability (Akinyemi, 2017), land change between 1986 and 2014 (Akinyemi \& Mashame, 2018), related plant species metrics to vegetation degradation levels between 1986 and 2016 (Akinyemi \& Kgomo, 2019), and LD as of 2015 using the Composite Land Degradation Index (CLDI) (Akinyemi et al., 2019).

\section{RESULTS}

\subsection{Land cover transitions and degradation}

Based on the NM (Fig. 3), 76\% (434049 $\mathrm{km}^{2}$ ) of the total land area remained unchanged, i.e. persistence, between 2000 and 2015. Figure 3a depicts areas of LC category losses, i.e. areas of displacement, Figure 3b depicts the amount of land area gained by each land category and from which categories, and Figure 3c shows the spatial distribution of degrading land transitions. For example, areas of grassland loss in Figure 3a mostly corresponded to areas 
of improvement in Figure 3c. Areas of forest loss corresponded mostly to areas of degradation. Table 2 shows estimates of land area under each land transition.

Insert Figure 3 here

Insert Table 2 here

Much of the gains made in tree-covered areas (76\%, $\left.49165 \mathrm{~km}^{2}\right)$, croplands (93\%, 38034 $\mathrm{km}^{2}$ ) and otherland (91\%, $18116 \mathrm{~km}^{2}$ ) were derived from grasslands, whereas gains made by grassland were mostly from tree-covered areas $\left(3 \%, 13450 \mathrm{~km}^{2}\right)$, otherland $\left(2 \%, 6273 \mathrm{~km}^{2}\right)$, and croplands $\left(1 \%, 2075 \mathrm{~km}^{2}\right)$. Of all LC types, grasslands transitioned the most to other cover types having lost 17\% (88746 $\left.\mathrm{km}^{2}\right)$ of its land area in 2015.

\subsection{Loss of land productivity}

LPD is depicted in Figure 4a. Areas of significant increasing vegetation productivity are mostly in the west, south of the Okavango Delta, whereas the eastern parts of Botswana were mostly stable. Areas with declining productivity in Figure 4a are in the south-east, and central, whereas some areas such as in south-west Kgalagadi are stable but stressed.

Examining land productivity in areas of LC persistence, i.e. 'no change’ areas (Figure 4c), we found that $72 \%$ of persistent tree-covered areas were stable, $10 \%$ were increasing in productivity, 1\% experienced declining productivity, and 17\% experienced moderate decline. The decline in productivity in LC persistent areas was highest in artificial surfaces (11\%). 
Although croplands with declining productivity were minimal (2\%) and $60 \%$ of croplands have stable productivity, about $36 \%$ of croplands already show early signs of decline in productivity. In areas of LC transitions, specifically category loss areas, land productivity increased most where otherland was converted to other categories (22\%). In areas of forest loss, land productivity declined by $2 \%$, whereas $26 \%$ show early signs of decline. In areas of cropland loss, only $1 \%$ experienced productivity decline, whereas $22 \%$ show early signs of decline.

\section{Insert Figure 4 here}

\subsection{Degradation of soil organic carbon}

As an indicator of soil quality, depletion in SOC impedes the soil water holding and ion exchange capacities determining its moisture and nutrient retention (Raich \& Schlesinger, 1992; UNCCD, 2018). Since SOC is a useful indicator of longer-term changes in land productivity due to its typical slow rate of change, only minimal changes may be observed between reporting periods (Elbehri et al., 2017; Sims et al., 2019). SOCs for 2015, SOC change (2000-2015), and SOCs degradation are depicted in Figure 5. Change in SOCs between the baseline (2000) and target (2015) years was minimal (Fig. 5b). SOCs decreased under tree-covered area by 0.2 t/ha, whereas it increased by 2.3 t/ha under croplands and 2.1 
t/ha under artificial surface areas. The amounts of land area concerned for each of these years are also presented in $\mathrm{km}^{2}$ (Fig 5b). Overall, LC transitions over the 15-year period resulted in a 3.3\% net gain in SOCs. The 2015 SOCs map (Figure 5a) was visually compared with the carbon map over Southern Africa (Scharlemann et al., 2009) and values were within the ranges estimated by Thomas et al. (2012) for south-west Kalahari $(<39 \mathrm{t} / \mathrm{ha})$, and the Makgadikgadi salt pans in north-eastern Botswana (> 50 t/ha).

\title{
Insert Figure 5 here
}

\subsection{Land degradation status}

SDG 15.3.1 was computed as the proportion of degraded land over total land area in 2015 using the DD (Fig. 6a) and NM (Fig. 6b). The values for the three LDN sub-indicators and SDG 15.3.1 estimated using the DD were compared to the NM (Fig. 6c). We observed a marked improvement in estimates when the NM (tier 2 data) are used. For example, estimates of degraded land reduced from 51.4\% (DD) to 32.6\% (NM), whereas estimates of 'Improved' land increased from 1.4\% (DD) to 15.8\% using the NM. Degraded areas consistent with both methods are in the south-eastern, southern, and central parts of Botswana.

\author{
Insert Figure 6 here
}

\subsection{Validation}


Although field validation of remote sensing products is very essential, this is grossly lacking in many studies assessing the LDN and SDG 15.3.1. UNCCD (2018) describes likely uncertainties and errors in the various sub-indicators and data sources. They emphasized the need for local data and expertise when disagreements and uncertainties are found in default estimates of degraded land. To validate the proportion of degraded land estimated by the NM and DD, we used the 2015 CLDI data for Palapye (Akinyemi et al., 2019). Since the NM and DD are different from the CLDI, a one-to-one direct matching between their classes was impossible. Instead, the NM and DD maps were related to the CLDI based on the spatial intersection of their LD classes (Fig. 7a, b). As multiple classes occurred in a single CLDI physiographic unit, the most frequent LD class, i.e. mode, was adopted for that unit. A matching scheme of the possible combinations of classes between the maps was developed using the $1 \mathrm{OAO}$ rule (Fig. 7c). Comparing LD classes in the three datasets over Palapye (Fig.7d), NM and DD underestimated the 'Improved' class by $12 \%$ and $88 \%$ respectively. NM overestimated the 'Stable' class by 17\%, whereas DD underestimated 'Stable' by 75\%. NM and DD overestimated the 'Degraded' class 21\% and 267\% respectively. Thus, NM estimates better match the CLDI than does the DD.

\section{Insert Figure 7 here}

\section{DISCUSSION}

This article is protected by copyright. All rights reserved. 
As a contribution to LDN baseline setting in all countries, this study developed a remote sensing-based procedure for assessing LD. Using the example of Botswana, we developed high resolution national level datasets of land cover, land productivity dynamics and soil organic carbon stock for estimating the proportion of degraded land (SDG 15.3.1) between 2000 and 2015. It contrasted estimates of the proportion of degraded land using the global default datasets and national metrics. Going beyond LD assessments, it also demonstrated how to validate land degradation using field-based data.

\subsection{Land cover degradation}

Tree-covered areas increased mainly due to gains from grasslands, whereas losses, interpreted as degrading, were minimal as forests transitioned to grasslands, otherland, and water bodies. This increase attests to efforts at reforestation and afforestation. For example, the nursery programme had a total national production of 603,363 seedlings in 2001/2002 (Central Statistics Office, 2004). The main drivers of forest loss in Botswana are wildfire, damage by animals such as Elephants (Chase, 2013), deforestation (DFRR, 2017), droughts (Forest Conservation Botswana-FCB, 2013), and dam construction (Akinyemi \& Mashame, 2018). Settlements also expanded into grasslands, tree-covered areas, and croplands.

Based on our estimates from the Landsat-based map, tree-covered areas were underestimated at $11 \%$ of the total land area in comparison to $27 \%$ in the Botswana Forest Distribution Map of 2015 (DFRR, 2017). This underestimation is probably due to the 
inclusion of woody shrubs in the grassland category for this study. The Botswana landscapes are often a mix of trees, shrubs, and grasses such as in south-west Kalahari (Thomas et al., 2012). At 7\% of the total land area in 2015 based on our results, croplands seem overestimated when compared with FAO data which puts cropland at $0.5 \%$ in 2015 (Statistics Botswana, 2018). Studies comparing cropland estimates for Africa from various sources have found higher estimates from remote sensing than FAO-based data (Xiong et al., 2017; Liu et al., 2018). This is attributed mainly to the fact that FAO data are largely compiled statistics from government sources despite different methods and definitions of croplands being utilized by countries.

\subsection{Loss of land productivity}

Productivity decline was highest in artificial surfaces since vegetation is often replaced with concrete in settlements. Although majority of croplands are stable, about one-third of croplands show early signs of decline. For example, early signs of decline in croplands are evident in the Central district which has the highest number of agricultural holdings in Botswana (Statistics Botswana, 2015). Sustainable land management practices ought to be implemented as LD can hamper agricultural productivity and food security.

Areas with significant vegetation productivity decrease or increase are not necessarily degraded or improved (Sims et al., 2019) and must be interpreted as appropriate within the 
local context of land uses and management practices (Reed et al., 2015). For example, some vegetation productivity increases in west and north-west Botswana are likely due to bush encroachment judging from the findings of previous studies on Botswana semi-arid rangelands (Reed et al., 2015; Akinyemi \& Kgomo, 2019). Bush encroachment is often undesirable in cattle-based systems since it is linked to reduced tree species diversity, increased woody (shrub) biomass, dominance of unpalatable grass species and biophysical impacts in rangelands (Thomas et al., 2018). Although remote sensing vegetation indices are useful indicators of vegetation conditions, these associate bush encroachment with increasing trends of vegetation greening in rangelands (Brandt et al., 2017). Thus, remote sensing is limited in distinguishing bush encroachment from other vegetation cover types (Karnieli et al., 2013). Hence, to correctly interpret and map bush encroachment as rangeland degradation from images, very intensive field data collection of multiple time points for ground truthing is required. Including such data to further refine the image classification process, e.g. differentiating between an 'afforested' class and a 'wood encroached' class is highly recommended in land degradation monitoring.

\subsection{Soil organic carbon degradation}

The net-gain of 3.3\% in SOCs is attributed mainly to gains made by tree-covered areas and croplands from grasslands over the 15-year study period. SOCs amount per hectare (t/ha) found in forested land decreased although the amount of forested land increased over the 
study period. Under croplands, SOCs amount (t/ha) increased as croplands expanded. Given that SOC is an indicator of soil quality and increase implies improvement in soil fertility and productivity (FAO 2017, 2018; UNCCD, 2018), it is unexpected to find that SOCs increased per hectare of land under artificial surfaces over the study period. Gichenje and Godinho (2018) in their Kenyan study found that SOC and NPP values were high for settlement areas. The finding that majority of persistent artificial surfaces and loss areas had improved and/or stable land productivity, 53\% and 68\% respectively, could help explain this slight increase in SOCs values in artificial surface areas. Another probable reason is that SOCs improved as land productivity increased in areas where otherlands were converted, mostly to settlements.

The occurrences of land productivity and SOCs improvement in artificial surface areas present a policy option for Botswana to better leverage its expanding human settlements for carbon storage. This is supported by findings from studies examining urban environments as carbon storage such as Zhao et al. (2007) and Churkina et al. (2010). Conversion of otherlands or croplands to settlements with parks and lawns may be beneficial as carbon uptake and storage might increase with more vegetation cover (Zhao et al., 2007). In the conterminous United States, Churkina et al., (2010) attributed 10\% of total land carbon storage to settlements with $64 \%$ of this carbon found in soils, $20 \%$ in vegetation, $11 \%$ in landfills, and 5\% in buildings. Other studies found differential impacts of land cover change on SOCs in varying settlement densities (Edmonson et al., 2014, Sun et al., 2019). Edmonson et al. (2014) examined urban greenspaces in Leicester, UK and found that domestic gardens 
held greater SOCs concentrations than non-domestic greenspaces. In Beijing, Sun et al. (2019) found carbon declined with increasing urban density. Based on the national development plan to provide Botswana’s population with decent and affordable housing, land demand for residential, commercial, and infrastructural development is expected to increase in the future. In Palapye for example, settlement expansion is projected to increase from 72 to $344 \mathrm{~km}^{2}$ by 2028 (Akinyemi \& Mashame, 2018). Consequently, a better understanding of the role of human settlements as carbon storage in Botswana is needed.

\subsection{Estimating and validating the proportion of degraded land}

This study estimated the proportion of degraded land over total land area based on degradation in the three LDN sub-indicators. Degraded land estimates using the DD (51.4\%, $\left.296717 \mathrm{~km}^{2}\right)$ improved with the use of NM (32.6 \%, $\left.182985 \mathrm{~km}^{2}\right)$, hence justifying the extra effort put into producing national level datasets for LDN setting. This study checked and confirmed this claim of improvement in LD estimates by field verification over Palapye, eastern Botswana where the CLDI data, a comprehensive land degradation field-based data, exist. NM and DD estimates of LD were compared to the CLDI. Comparing the occurrence of LD in the NM and DD to the CLDI, NM estimates were closest to the CLDI. With the possibility to develop a Botswana national carbon stock database and generate more fieldbased data on land change and LPD, estimates will further improve.

\section{Conclusions}


LD is taking place in all agro-ecological zones and has long-lasting impacts on people and the environment. Despite the importance of the problem of LD and its acknowledgment at a global level, until recently, no consensus has been achieved on systematic and standardized approaches for LD monitoring and assessment. This situation was changed when UNCCD proposed a guided methodology to compute LDN baseline and assess indicators related to SDG target 15.3.

In this study, we successfully assessed LDN and SDG indicator 15.3.1 using two approaches: First, using default datasets (DD) as recommended by UNCCD, and second, national metrics (NM) that we developed using freely available satellite based datasets, such as from Landsat and MODIS, as well as in situ data. We further validated our LD estimates using field-based data for a case study in eastern Botswana. The estimates derived from coarse resolution DD are not suitable for policy-making or for localised investigations of the potential land rehabilitation measures. Our research proved that the use of NMs is welljustified considering that they contribute to more accurate derivatives of LD's indicators and to LDN baseline estimates. The provision of spatially explicit information on degraded land would make it possible to better target sustainable land management (SLM) efforts to prioritized areas in need of immediate attention and to facilitate land rehabilitation planning in Botswana.

Because of data constraints and the absence of validation datasets for the whole of Botswana, the LD assessment performed here can serve only for general planning purposes. 
Our results, however, generated an improved information on the SDG 15.3.1 indicators and LDN baseline and can serve as the foundation for SLM and land rehabilitation planning in Botswana.

The proposed approach in this study shows how more accurate national level datasets for LD assessment and monitoring can be derived in comparison to the DD datasets. The herein demonstrated approach is based on open-source data and can be easily transferred to other countries, particularly those with similar environmental settings. The study also demonstrated how to conduct LD validation with field-based data. Subject to data availability, our methodology can be further extended by utilizing images of higher spatial resolution than those used in this study such as from Sentinel missions of the European Copernicus programme. This could be done, for instance, for creating more recent LC maps based on Sentinel-1 and 2 image data. For calculating LPD trends, the use of Landsat time series is most optimal at this current time because of the short-term nature of the Sentinel archives.

\section{Acknowledgments}

The Alexander von Humboldt Foundation, Bonn, Germany generously provided finance for my research visit at the Centre for Remote Sensing of Land Surfaces (ZFL), University of Bonn, Germany. Special thanks to Professor Klaus Greve my host professor and Dr. Javier González for assistance with codes. The use of the land cover field data (2018) collected by 
Gomolemo Mokibe, Lucky Moeng, and Peter Kesaobaka is acknowledged. The comments from the anonymous reviewers are highly appreciated.

\section{Conflict of Interest}

The authors declare that they have no conflict of interest.

\section{References}

Akinyemi, F.O. (2017). Climate change and variability in semi-arid Palapye, Eastern Botswana: An assessment from smallholder farmers' perspective. Weather Clim Soc, 9(3), 349-365. doi:10.1175/WCAS-D-16-0040.1

Akinyemi, F.O., \& Mashame, G. (2018). Analysis of land change in the dryland agricultural landscapes of eastern Botswana. Land Use Policy, 76, 798-811. doi: $\underline{10.1016 / j . l a n d u s e p o l .2018 .03 .010}$

Akinyemi, F.O., \& Kgomo, M.O. (2019). Vegetation dynamics in African drylands: An assessment based on the Vegetation Degradation Index in an agro-pastoral region of Botswana. Regional Env Change, 19(7), 2027-2039. doi:10.1007/s10113-019-01541-4

Akinyemi, F.O., Tlhalerwa, L.T., \& Eze P.N. (2019). Land degradation assessment in an African dryland context based on the Composite Land Degradation Index and Mapping method. Geocarto International, doi:10.1080/10106049.2019.1678673 
Aynekulu, E., Lohbeck, M., Nijbroek, R., Ordóñez, J.C., Turner, K.G., Vågen, T., Winowiecki, L. (2017, November 15). Review of methodologies for land degradation neutrality baselines: Sub-national case studies from Costa Rica and Namibia. International Center for Tropical Agriculture publication no. 441. Retrieved from http://hdl.handle.net/10568/80563

Brandt, M., Tappan, G., Diouf, A.A., Beye, G., Mbow, C., Fensholt, R. (2017). Woody vegetation die off and regeneration in response to rainfall variability in the West African Sahel. Remote Sens, 9(1), 39. doi: 10.3390/rs9010039

Central Statistics Office (2004, November 15). Forestry statistics. Gaborone: Central Statistics Office. http://www.statsbots.org.bw/sites/default/files/publications/Forestry\%20Statistics.pdf

Chase, M. (2013, October 4) Status of wildlife populations and land degradation in Botswana’s forest reserves and Chobe district. Kasane: Elephants without borders. http://elephantswithoutborders.org/downloadspapers/ChobeDistrict2012AerialSurveyRe port.pdf

Chasek, P., Safriel, U., Shikongo, S., Fuhrman, V.F. (2015). Operationalizing Zero Net Land Degradation: The next stage in international efforts to combat desertification? Journal of Arid Environments, 112(5), 13. doi:10.1016/j.jaridenv.2014.05.020 
Churkina, G., Brown, D.G., \& Keoleian, G. (2010). Carbon stored in human settlements: The conterminous United States. Glob Chang Biol, 16, 135-143. doi:10.1111/j.13652486.2009.02002.x

Clark, D.A., Brown, S., Kicklighter, D.W., Chambers, J.Q., Thomlinson, J.R., Ni, J. (2001). Measuring net primary production in forests: Concepts and field methods. Ecol. Appl, 11, 356-370. doi:10.1890/1051-0761(2001)011[0356:MNPPIF]2.0.CO;2

De Jong, R., de Bruin, S., de Wit, A., Schaepman, M.E., Dent, D.L. (2011). Analysis of monotonic greening and browning trends from global NDVI time-series. Remote Sens Environ, 115, 692-702.

DFRR (2017, October 5). Enhancing national forest monitoring system for the promotion of sustainable natural resource management project report. Gaborone: Ministry of Environment, Natural Resources Conservation and Tourism (MENT). http://open_jicareport.jica.go.jp/pdf/12301594_01.pdf

Dubovyk, O., Landmann, T., Erasmus, B.F.N., Tewes, A. \& Schellberg J. (2015). Monitoring vegetation dynamics with medium resolution MODIS-EVI time series at sub-regional scale in southern Africa. Int. J Appl Earth Obs Geoinf, 38, 175-183. doi:10.1016/j.jag.2015.01.002

Dubovyk, O., Menz, G., Khamzina, A. (2016). Land suitability assessment for afforestation with Elaeagnus Angustifolia L. in degraded agricultural areas of the lower Amu Darya river basin. Land Degrad Dev, 27, 1831-1839. doi:10.1002/ldr.2329 
Duarte-Guardia, S., Peri, P.L., Borchard, N. Ladd, B. (2019). Soils need to be considered when assessing the impacts of land-use change on carbon sequestration. Nat Ecol Evol doi:10.1038/s41559-019-1026-8

Edmondson, J.L., Davies, Z.G., McCormack, S.A., Gaston, K.J., Leake, J.R. (2014). Landcover effects on soil organic carbon stocks in a European city. Science of The Total Environment, 472, 444-453. doi:10.1016/j.scitotenv.2013.11.025

Elbehri, A., Challinor, A., Verchot, L., Angelsen, A., Hess, T., Ouled Belgacem, A., ...\& Walker, R. (2017, April 15). Expert Meeting Report on Climate Change, Land Use and Food Security. $\quad$ Rome: FAO and IPCC. https://www.ipcc.ch/site/assets/uploads/2018/08/EM_FAO_IPCC_report.pdf

FAO. (2017). The future of food and agriculture - Trends and challenges. FAO: Rome. http://www.fao.org/3/a-i6583e.pdf

FAO. (2018). The future of food and agriculture-Alternative pathways to 2050. FAO: Rome. http://www.fao.org/3/I8429EN/i8429en.pdf

FCB (2013, October 6). Forest management and use in Botswana: Brief situation analysis and options for the Forest Conservation Strategy. https://library.wur.nl/ojs/index.php/Botswana_documents/article/download/15980/15453

Foster RH. 2006. Methods for assessing land degradation in Botswana. Earth \& Environment $1: 238-276$. 
Gichenje, H.H., \& Godinho, S. (2018). Establishing a land degradation neutrality national baseline through trend analysis of GIMMS NDVI Time-series. Land Degrad Dev, 29(9), 2985-2997.doi:10.1002/ldr.3067

Ghazaryan, G., Dubovyk, O., Löw, F., Lavreniuk, M., Kolotii, A., Schellberg, J., \& Kussul, N. (2018). A rule-based approach for crop identification using multi-temporal and multisensor phenological metrics. European Journal of Remote Sensing, 51(1), 511-524. doi: $\underline{10.1080 / 22797254.2018 .1455540}$

Gonzalez-Roglich, M., Zvoleff, A., Noon, M., Liniger, H., Fleiner, R., Harari, N., Garcia, C. (2019). Synergizing global tools to monitor progress towards land degradation neutrality: Trends.Earth and the World Overview of Conservation Approaches and Technologies sustainable land management database. Environ Sci Pol 93: 34-42, doi:10.1016/j.envsci.2018.12.019

Government of Botswana (2016, November 16). Vision 2036-Achieving prosperity for all. Gaborone: Lentswe La Lasedi (Pty) Ltd. http://www.statsbots.org.bw/sites/default/files/documents/Vision\%202036.pdf.

Government of Botswana (2018, January 25). Report from Botswana. UNCCD Performance Review and Assessment of Implementation System $7^{\text {th }}$ reporting process. https://prais.unccd.int/sites/default/files/pdf_reports/unccd_Botswana_2018_1.pdf 
Hao, P., Wang, L., Zhan, Y., Wang, C., Niu, Z., \& Wu, M. (2016). Crop classification using crop knowledge of the previous-year: Case study in Southwest Kansas, USA. European Journal of Remote Sensing, 49(1), 1061-1077.

Higginbottom, T.P., \& Symeonakis, E. (2014). Assessing land degradation and desertification using vegetation index data: Current frameworks and future directions. Remote Sensing, 6, 9552-9575. doi:10.3390/rs6109552

Hengl, T., de Jesus, J.M., Heuvelink, G.B.M., Gonzalez, M.R., Kilibarda, M., Blagotić, A., ... Kempen, B. (2017). SoilGrids250m: Global gridded soil information based on machine learning. PLoS one, 12(2), e0169748. doi:10.1371/journal.pone.0169748

Karnieli, A., Bayarjargal, Y., Bayasgalan, M., Mandakh, B., Dugarjav, C., Burgheimer, J., Khudulmur, S., Bazha, S.N., Gunin, P.D. (2013). Do vegetation indices provide a reliable indication of vegetation degradation? A case study in the Mongolian pastures. Int J Remote Sens 34(17):6243-6262. 10.1080/01431161.2013.793865

Kayombo, B., Meulenburg, F., Moganane, B.G., Dikinya, O., Aliwa, J.N., Nsinamwa M., ... Machacha, S. (2005). Characterization of agriculture-related land degradation in eastern and western parts of Botswana. Botswana Journal of Technology, 14, 1-10.

Lanfredi, M., Coppola, R., Simoniello, T., Coluzzi, R., D'Emilio, M., Imbrenda, V., \& Macchiato, M. (2015). Early identification of land degradation hotspots in complex biogeographic regions. Remote Sensing, 7(6), 8154-8179. 
Liu, X., Yu, L., Li, W., Peng, D., Zhong, L., Li, L., Xin, Q., Lu, H., Yu, C., Gong, P. (2018). Comparison of country-level cropland areas between ESA-CCI land cover maps and FAOSTAT data. International Journal of Remote Sensing, 39:20, 6631-6645. https://doi.org/10.1080/01431161.2018.1465613

Maxwell, A.E., Warner, T.A. \& Fang, F. (2018). Implementation of machine-learning classification in remote sensing: An applied review. International Journal of Remote Sensing, 39(9), 2784-2817. doi:10.1080/01431161.2018.1433343

MFDP (2016, November 11). Draft National Development Plan 11 April 2017-March 2023 (201 pp). http://www.baisago.ac.bw/common_up/isago/pub_1484811759.pdf

Nkonya, E., Johnson, T., Kwon, H.Y., Kato, E. (2016). Economics of land degradation in sub-Saharan Africa. In: Nkonya, E., Mirzabaev, A., von Braun, J. (Eds.) Economics of land degradation and improvement - A global assessment for sustainable development (pp. 215-259). Cham: Springer. doi:10.1007/978-3-319-19168-3_9

Pesaresi, M., Ehrilch, D., Florczyk, A.J., Freire, S., Julea, A., Kemper, T.P., Syrris, V. (2015). GHS built-up grid, derived from Landsat, multitemporal (1975, 1990, 2000, 2014). European Commission Joint Research Centre Dataset PID. http://data.europa.eu/89h/jrcghslghs_built_ldsmt_globe_r2015b

Raich, J.W., \& Schlesinger W.H. (1992). The global carbon dioxide flux in soil respiration and its relationship to vegetation and climate. Tellus, Series B: Chemical and Physical Meteorology, 44, 81-89. 
Reed, M.S., Stringer, L.C., Dougill, A.J., Perkins, J.S., Atlhopheng, J.R., Mulale, K., Favretto, N. (2015). Reorienting land degradation towards sustainable land management: Linking sustainable livelihoods with ecosystem services in rangeland systems. $J$ Environ Manage, 151, 472-485 doi:10.1016/j.jenvman.2014.11.010

Scharleman, J.P.W., Hiederer, R., Kapos, V. \& Ravilious, C. (2009). Updated global carbon map. Cambridge: UNEP-WCRC \& EU-JRC.

Sebego, R.J., Atlhopheng, J.R., Chanda, R., Mulale, K. \& Mphinyane, W. (2019). Land use intensification and implications on land degradation in the Boteti area: Botswana. African Geographical Review, 38(1), 32-47, doi:10.1080/19376812.2017.1284599

Sims, N.C., England, J.R., Newnham, G.J., Alexander, S., Green, C., Minelli, S., Held, A. (2019). Developing good practice guidance for estimating land degradation in the context of the United Nations Sustainable Development Goals. Environ Sci Pol, 92, 349-355. doi:10.1016/j.envsci.2018.10.014

Sommer, S., Zucca, C., Grainger, A., Cherlet, M., Zougmore, R., Sokona, Y., Hill, J., ...\& Wang, G. (2011). Application of indicator systems for monitoring and assessment of desertification from national to global scales. Land Degrad Dev, 22, 184-197. doi: $\underline{10.1002 / l d r .1084}$

Statistics Botswana (2015). Serowe/Palapye Sub-district Population and Housing Census 2011: Selected Indicators. Gaborone: Statistics Botswana. 
Statistics Botswana (2018, October 2). FAO resource statistics - Land 2015. Gaborone: Statistics Botswana. http://faostat3.fao.org/download/R/RL/F

Sun, Y., Xie, S., \& Zhao, S. (2019). Valuing urban green spaces in mitigating climate change: A city-wide estimate of aboveground carbon stored in urban green spaces of China's capital. Glob Chang Biol, 25(5), 1717-1732. doi:10.1111/gcb.14566

Thomas, A., Hoon, S.R., Mairs, H., \& Dougill, A.J. (2012). Soil organic carbon and soil respiration in deserts: Examples from the Kalahari. In Mol, L. \& Sternberg T. (Eds.), Changing deserts: Integrating people and their environment, pp. 40-60. Cambridge: White Horse Press.

Thomas, A.D., Elliott, D.R., Dougill, A.J., Stringer, L.C., Hoon, S.R., \& Sen, R. (2018). The influence of trees, shrubs, and grasses on microclimate, soil carbon, nitrogen, and CO2 efflux: Potential implications of shrub encroachment for Kalahari rangelands. Land Degrad Dev, doi:10.1002/ldr.2918

Trends.Earth (2019). Tracking land change. Conservational International. http://trends.earth/docs/en/pdfs/Trends.Earth.pdf

Tüshaus, J., Dubovyk, O., Khamzina, A., \& Menz, G. (2014). Comparison of medium spatial resolution ENVISAT-MERIS and terra-MODIS time series for vegetation decline analysis: A case study in central Asia. Remote Sensing, 6(6), 5238-5256. doi: $10.3390 /$ rs6065238 
UN (2015, July 16). Transforming our world: The 2030 Agenda for sustainable development. https://www.un.org/pga/wp-content/uploads/sites/3/2015/08/120815_outcomedocument-of-Summit-for-adoption-of-the-post-2015-development-agenda.pdf

UNCCD (2016, January 9). Land in balance. The scientific conceptual framework for land $\begin{array}{lllll}\text { degradation } & \text { neutrality } & \text { (LDN). } & \text { Science-Policy } & \text { Brief }\end{array}$ http://www2.unccd.int/sites/default/files/relevant-links/201701/18102016_Spi_pb_multipage_ENG_1.pdf

UNCCD (2018). Default data: Methods and interpretation. A guidance document for the 2018 UNCCD reporting. https://prais.unccd.int/sites/default/files/helper_documents/3DD_guidance_EN.pdf

Xie, S., Liu, L., Zhang, X., Yang, J., Chen, X., \& Gao, Y. (2019). Automatic land-cover mapping using Landsat time-series data based on Google Earth Engine. Remote Sensing, 11(24), 3023.

Xiong J, Thenkabail PS, Gumma MK, Teluguntla P, Poehnelt J, Congalton RG, Yadav K, Thau D 2017b. Automated cropland mapping of continental Africa using Google Earth Engine cloud computing. ISPRS Journal of Photogrammetry and Remote Sensing 126:225-244. https://doi.org/10.1016/j.isprsjprs.2017.01.019

Webb, N.P., Marshall, N.A., Stringer, L.C., Reed, M.S., Chappell, A., Herrick, J.E. (2017). Land degradation and climate change: Building climate resilience in agriculture. Frontiers in Ecology and the Environment, 15(8), 450-459. doi:10.1002/fee.1530 
Zhao, C., Zhou, Y., Li, X., Xiao, P., Jiang, J. (2018). Assessment of cultivated land productivity and its spatial differentiation in Dongting Lake region: A case study of Yuanjiang City, Hunan Province. Sustainability, 10, 3616. doi:10.3390/su10103616 
Table 1: Datasets used in this study

\begin{tabular}{|c|c|c|c|c|c|}
\hline $\begin{array}{l}\text { LDN sub- } \\
\text { indicator }\end{array}$ & Tier & Data & $\begin{array}{l}\text { Resolution/ } \\
\text { Year }\end{array}$ & Description & Remark/reference \\
\hline \multirow[t]{4}{*}{$\begin{array}{l}\text { Land cover } \\
\text { (LC) }\end{array}$} & $\begin{array}{l}\text { Tier } 1 \text { Default } \\
\text { data (DD) }\end{array}$ & $\begin{array}{l}\text { European Space Agency Climate } \\
\text { Change Initiative (ESA-CCI) LC }\end{array}$ & $\begin{array}{l}300 \mathrm{~m} \\
(1992-2015)\end{array}$ & $\begin{array}{l}\text { LC map has over } 30 \text { categores } \\
\text { aggregated }\end{array}$ & $\begin{array}{l}\text { https://www.esa- } \\
\text { landcover-cci.org/ }\end{array}$ \\
\hline & $\begin{array}{l}\text { Tier } 2 \\
\text { National } \\
\text { metrics (NM) } \\
\end{array}$ & $\begin{array}{l}\text { SERVIR/RCMRD Greenhouse } \\
\text { Gas Inventory (GHG) LC }\end{array}$ & $30 \mathrm{~m}(2000)$ & LC map has six categories & $\begin{array}{l}\text { http://apps.rcmrd.org/lan } \\
\text { dcoverviewer }\end{array}$ \\
\hline & NM & $\begin{array}{l}\text { Landsat 8, } \\
\text { Sentinel-1 }\end{array}$ & $\begin{array}{l}30 \mathrm{~m}(2015 \\
\text { and 2018) }\end{array}$ & $\begin{array}{l}\text { LC uses the same six } \\
\text { categories as the } 2000 \text { map }\end{array}$ & \\
\hline & $\begin{array}{l}\text { Tier } 3 \\
\text { Reference } \\
\text { data }\end{array}$ & $\begin{array}{l}\text { LC field data, high resolution } \\
\text { images in Google Earth Pro }\end{array}$ & 2018 & $\begin{array}{l}\text { GPS data of LC categories for } \\
\text { Gaborone, Mahalapye, and } \\
\text { Serowe. LC samples in } \\
\text { Botswana }\end{array}$ & \\
\hline \multirow{2}{*}{$\begin{array}{l}\text { Land } \\
\text { productivity } \\
\text { dynamics } \\
\text { (LPD) }\end{array}$} & DD & Joint Research Centre (JRC) LPD & $\begin{array}{l}1 \mathrm{~km}(2000- \\
2015)\end{array}$ & $\begin{array}{l}\text { Global LPD map has } 5 \\
\text { categories }\end{array}$ & $\begin{array}{l}\text { https://wad.jrc.ec.europa. } \\
\text { eu/landproductivity }\end{array}$ \\
\hline & NM & MODIS (MOD13Q1-coll6) & $\begin{array}{l}250 \mathrm{~m}(2000- \\
2015)\end{array}$ & NDVI & \\
\hline \multirow{2}{*}{$\begin{array}{l}\text { Soil organic } \\
\text { carbon } \\
\text { stocks } \\
\text { (SOCs) }\end{array}$} & DD & $\begin{array}{l}\text { International Soil Reference \& } \\
\text { Information Center } \\
\text { SoilGrids250m }\end{array}$ & $250 \mathrm{~m}$ & SOCs computed for 2000 & $\begin{array}{l}\text { https://files.isric.org/soil } \\
\text { grids/data/recent/ }\end{array}$ \\
\hline & NM & LC transitions map & $\begin{array}{l}30 \mathrm{~m}(2000- \\
2015)\end{array}$ & SOCs computed for 2015 & \\
\hline \multirow{2}{*}{\multicolumn{2}{|c|}{$\begin{array}{l}\text { Auxiliary data (training, } \\
\text { image classification, post- } \\
\text { processing, validation) }\end{array}$}} & $\begin{array}{l}\text { JRC Global Human Settlement } \\
\text { (GHS) }\end{array}$ & $38 \mathrm{~m}(2014)$ & Global urban areas of 2014 & $\begin{array}{l}\text { https://ghsl.jrc.ec.europa. } \\
\text { eu/ghs_pop.php }\end{array}$ \\
\hline & & $\begin{array}{l}\text { Monitoring the Environment } \\
\text { and Security for Africa (MESA- } \\
\text { SADC) cities }\end{array}$ & 30m, 2016 & $\begin{array}{l}\text { Data of settlement locations in } \\
\text { Southern African } \\
\text { Development } \\
\text { Community (SADC) }\end{array}$ & \\
\hline
\end{tabular}

This article is protected by copyright. All rights reserved. 


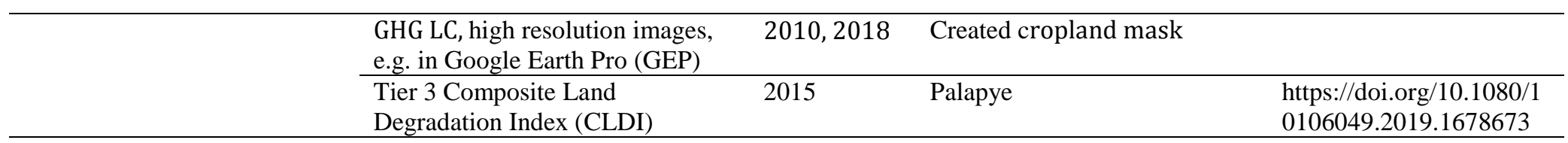

Table 2: Land cover transition matrix in $\mathrm{km}^{2}$ (2000 - 2015)

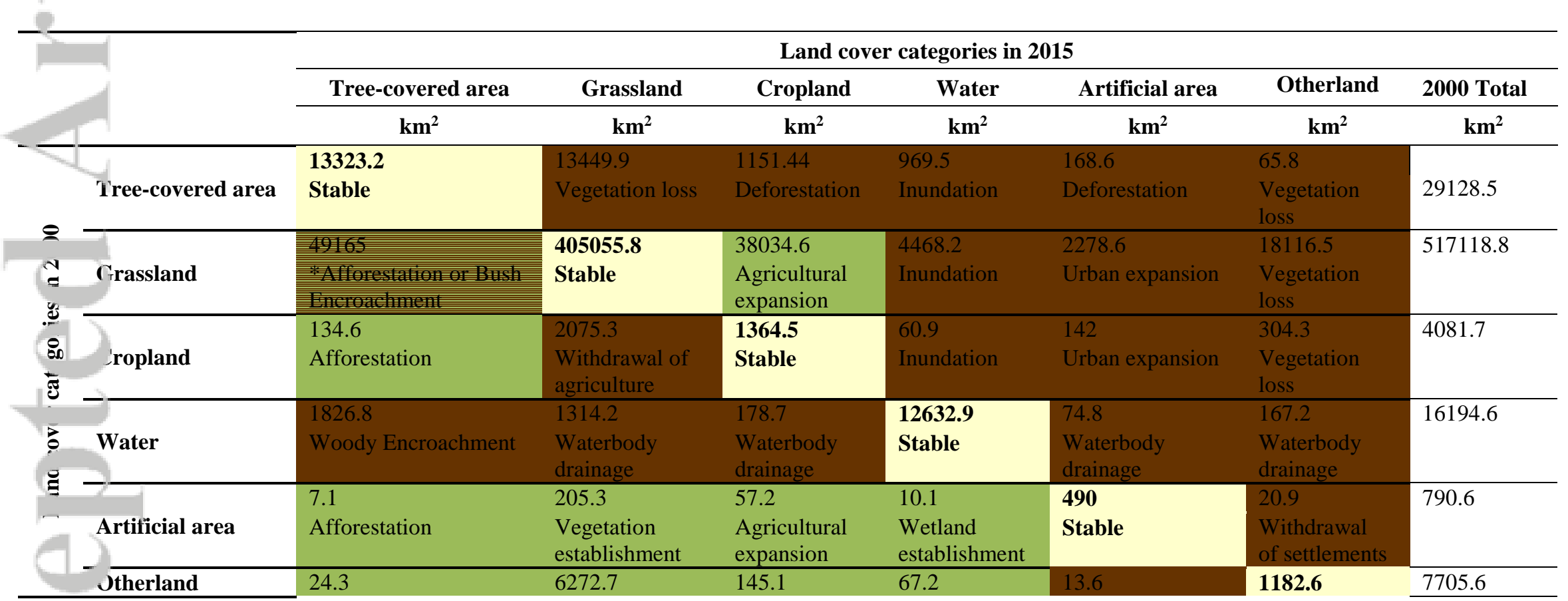

This article is protected by copyright. All rights reserved. 


\begin{tabular}{llllllll} 
& Afforestation & $\begin{array}{l}\text { Vegetation } \\
\text { establishment }\end{array}$ & $\begin{array}{l}\text { Agricultural } \\
\text { expansion }\end{array}$ & $\begin{array}{l}\text { Wetland } \\
\text { establishment }\end{array}$ & Urban expansion & Stable \\
\hline $\mathbf{2 0 1 5}$ Total $\left(\mathbf{k m}^{\mathbf{2}}\right)$ & 64480.9 & 428373.2 & 40931.6 & 18208.8 & 3167.7 & 19857.5 & 575019.7 \\
\hline
\end{tabular}

Note: *Although grassland conversion to tree-covered area is often interpreted as afforestation, there is the possibility that this transition could as well be due to bush encroachment, hence hash for improvement or degradation. Areas of land cover (LC) persistence (stable) are shown in bold. Corresponding LC transitions and land degradation classes were adapted from UNCCD (2018) and depicted using the same legend as the land cover degradation map (Fig.3c): green color for improvement, brown for degradation, and light yellow for stable. 


\section{Figure caption:}

Figure 1. The geographic and administrative setting of Botswana showing all districts and Gaborone city as capital

Figure 2. The workflow followed in this study

Figure 3. Changing land cover conditions and degradation based on national metrics during 2000 - 2015, a) Land category loss areas and persistence, b) land category gains (in square kilometre), c) land cover degradation.

Figure 4. Land productivity based on national metrics, a) Land productivity dynamics (2000-2015), b) land productivity change by land cover persistence and category level losses. Note that the water land cover category was excluded in the LPD since it is vegetation based, hence the values do not add up to the exact total land area of Botswana.

Figure 5. Soil organic carbon stocks (SOCs) based on national metrics, a) SOCs in 2015, b) change in SOCs, and c) degradation of soil organic carbon stock (2015)

Figure 6. Land degradation status (2015) using: a) Tier 1 data (Default Data - DD), and b) Tier 2 data (National Metrics - NM), c) LDN sub-indicators and land degradation status computed with DD and NM. Note that Botswana's total land area varied slightly between DD (577203 $\left.\mathrm{km}^{2}\right)$ and 
NM (560735 $\left.\mathrm{km}^{2}\right)$ as official boundary from the Botswana Department of Survey and Mapping was used for NM.

Figure 7. Validating land degradation in Palapye using the CLDI a) SDG 15.3.1 (National Metrics - NM) map with the CLDI physiographic unit boundaries superimposed. b) CLDI physiographic units with six land degradation classes, c) Matching the six CLDI land degradation classes to the three SDG 15.3.1 land degradation classes, d) Comparing the SDG 15.3.1 (NM and Default data - DD) with the CLDI.

When UNCCD land category nomenclature differs, it is shown in bracket alongside that of the GHG (UNCCD, 2018). 


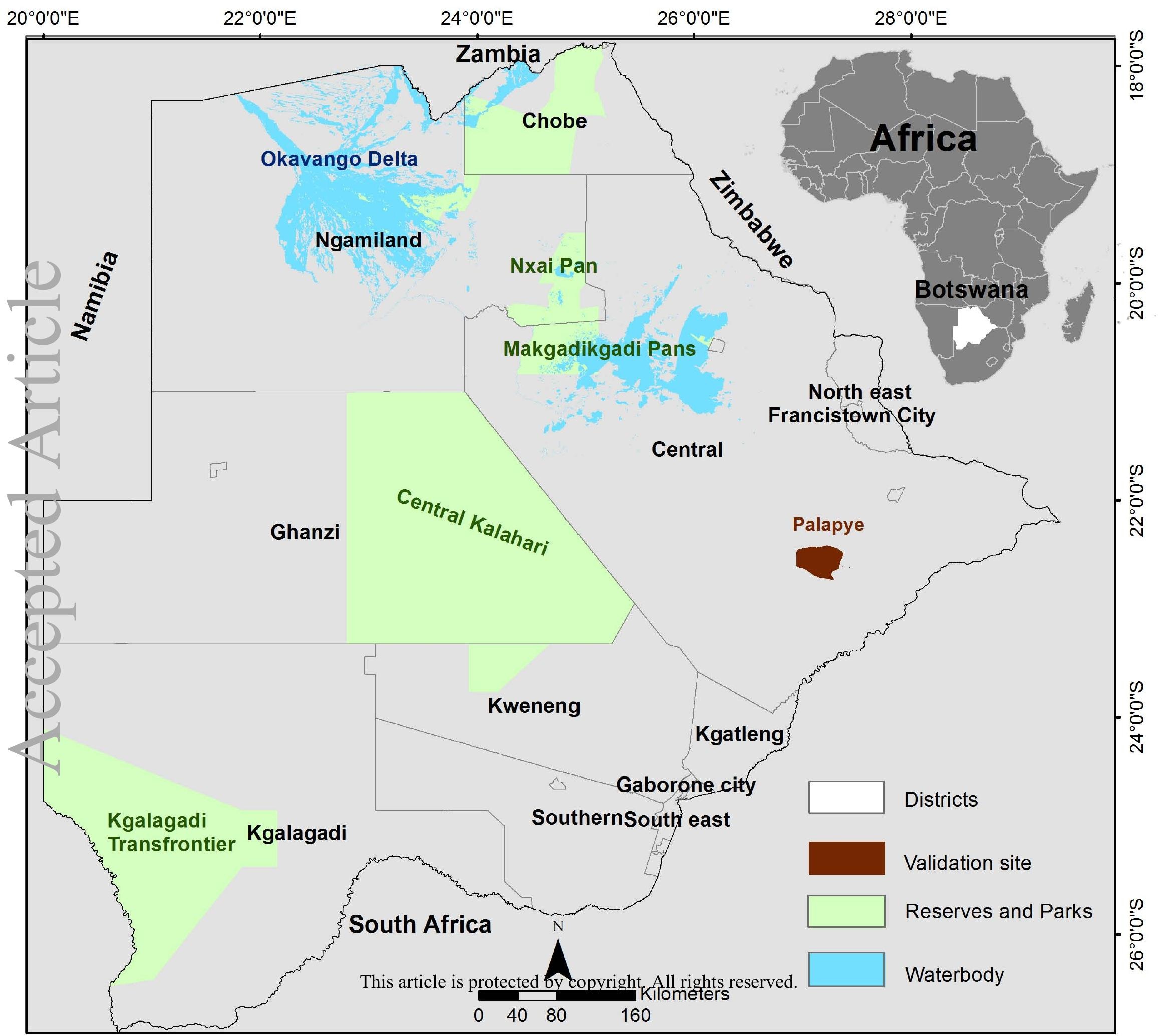




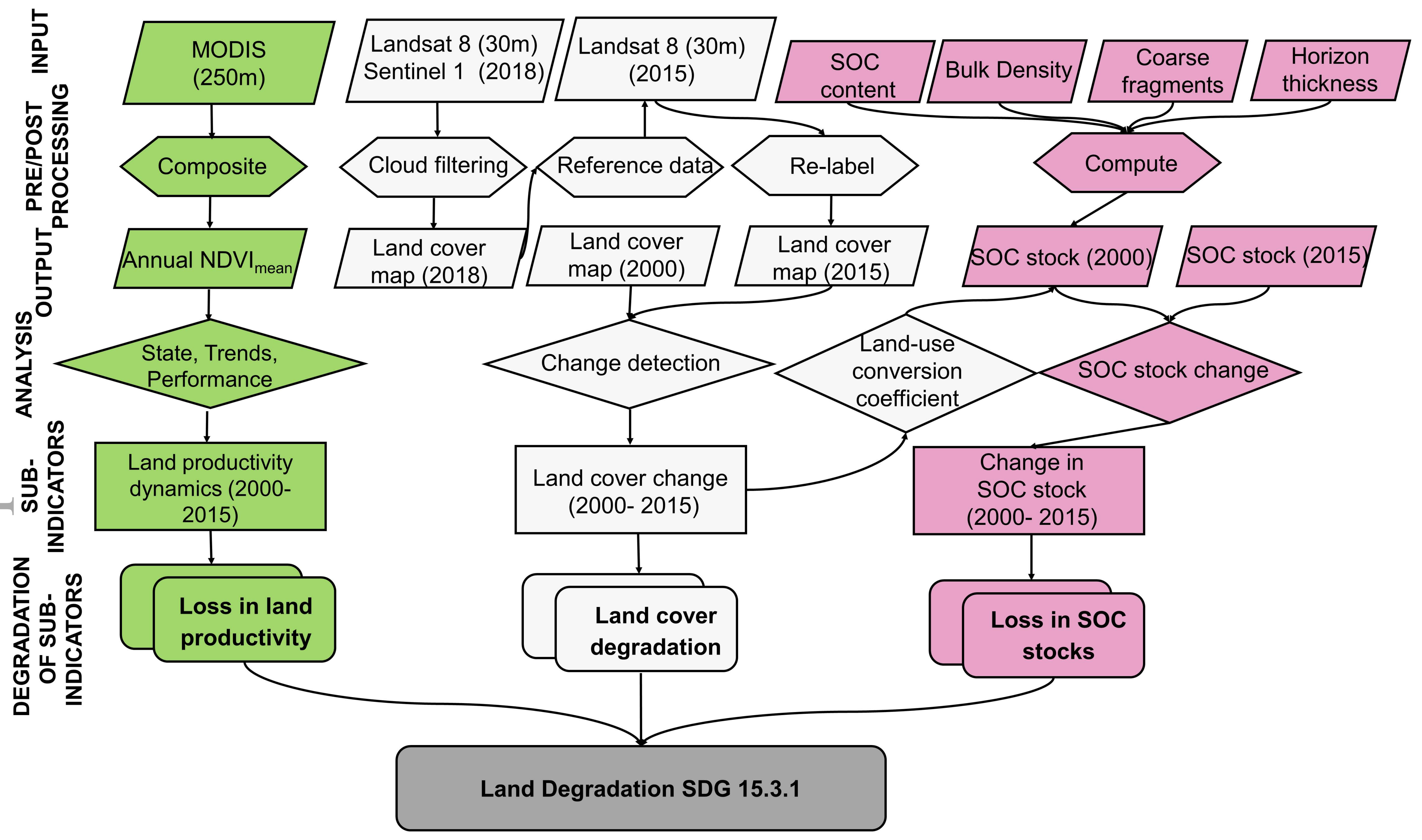




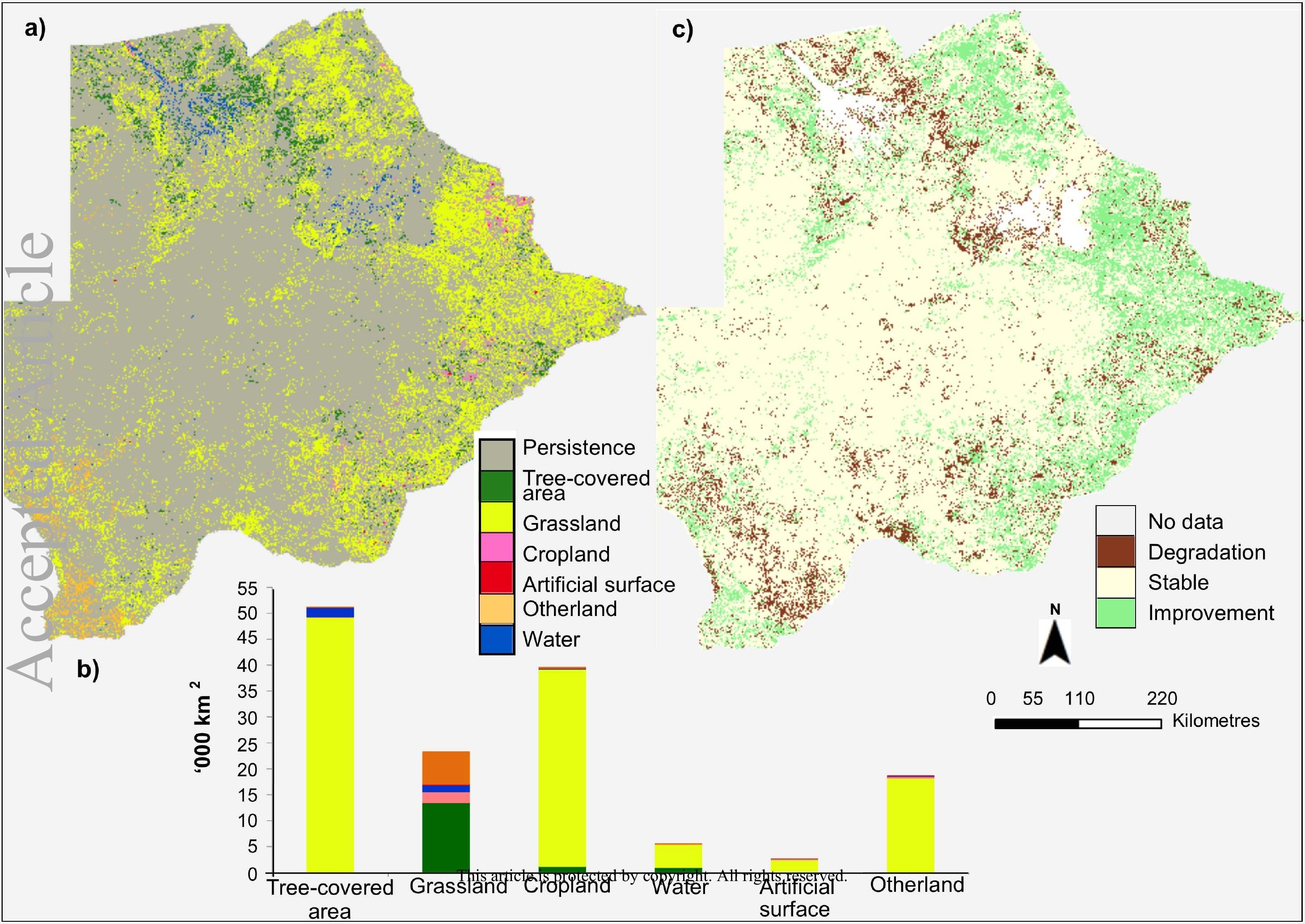




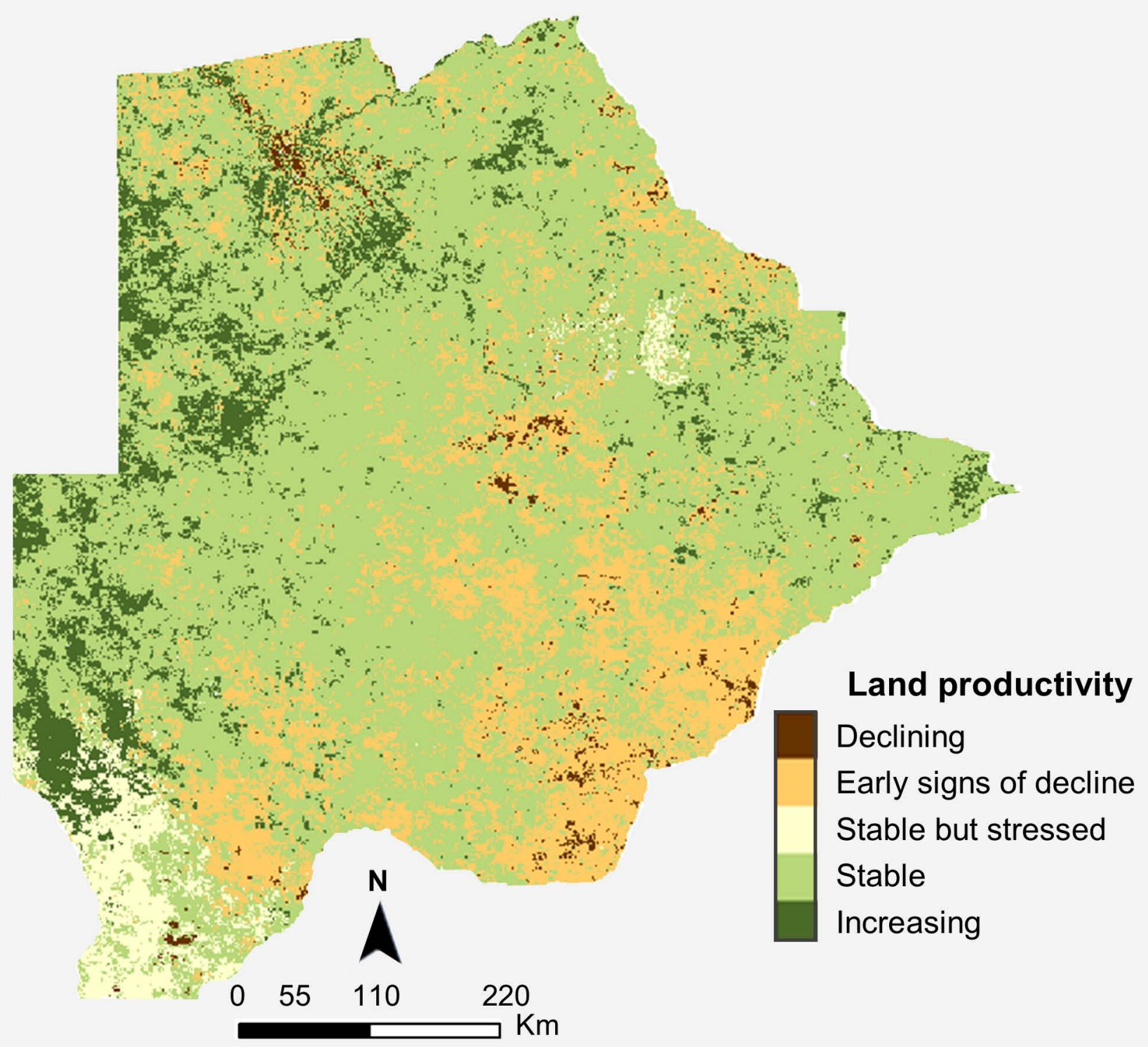

\begin{tabular}{|c|c|}
\hline & $2000-2015$ \\
\hline $\begin{array}{c}\text { Land } \\
\text { category } \\
\text { persistence }\end{array}$ & $\begin{array}{l}\text { Tree-covered } \\
\text { Grasslands } \\
\text { Croplands } \\
\text { Artificial surface } \\
\text { Otherland }\end{array}$ \\
\hline $\begin{array}{l}\text { Land } \\
\text { category } \\
\text { losses }\end{array}$ & $\begin{array}{l}\text { Tree-covered } \\
\text { Grasslands } \\
\text { Croplands } \\
\text { Artificial surface } \\
\text { Otherland }\end{array}$ \\
\hline
\end{tabular}

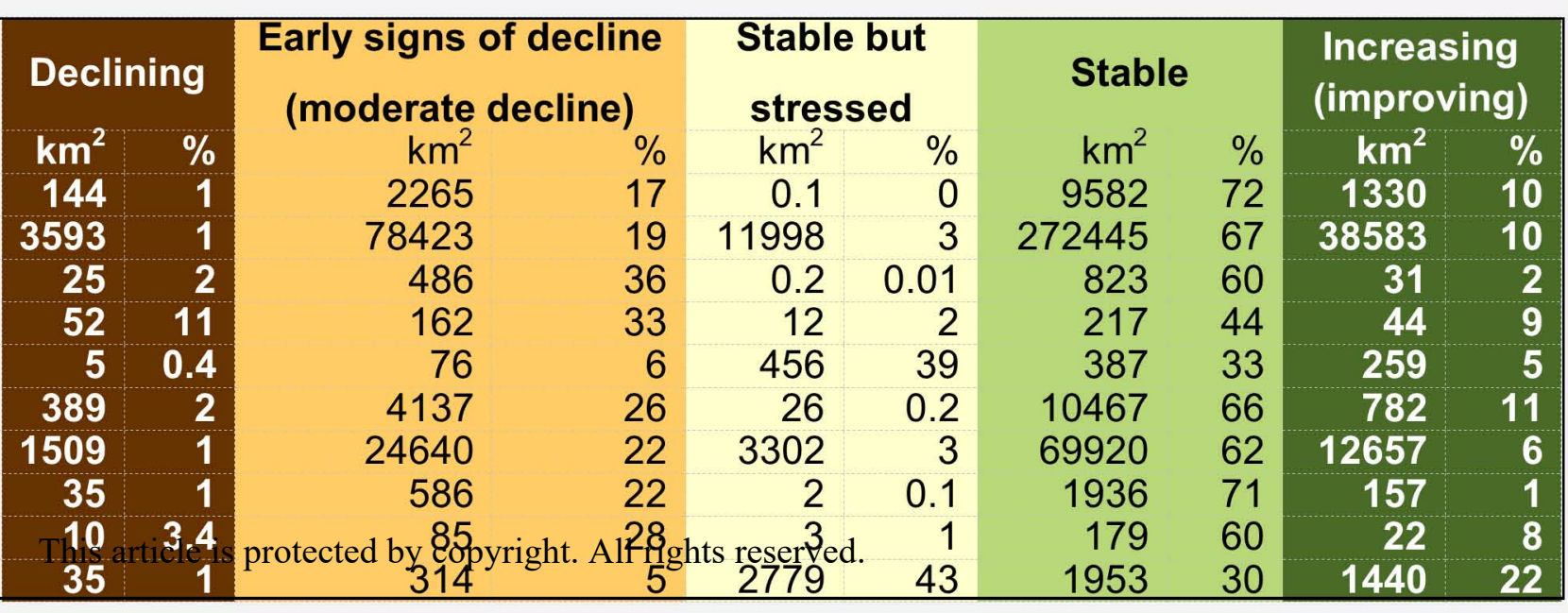




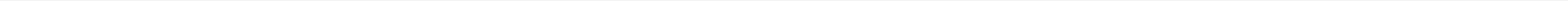




\section{a) SDG 15.3.1}

\% Improved

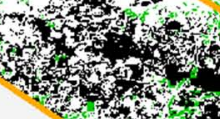

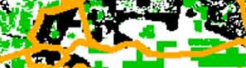

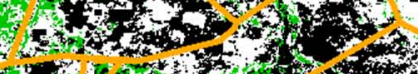

4

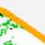

not

0

काष

$\frac{1}{4}$

Stable

Degraded

CLDI unit boundaries

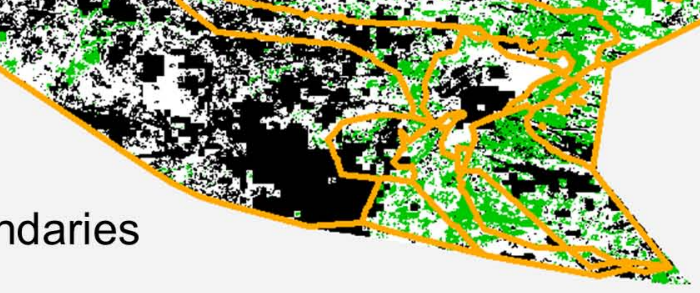

\section{C) SDG 15.3.1}

CLDI

Relatively undegraded Relatively undegraded

Stable

Degraded Relatively undegraded

Improved

Stable

Degraded Very low degradation Very low degradation

Improved

Stable Very low degradation Low degradation Low degradation

Degraded Low degradation Improved

Stable

Degraded Medium degradation

Improved Medium degradation

Stable Medium degradation

Degraded High degradation High degradation Improved

Stable Degraded
Matching

Improved

Improved

Improved

Stable

Degraded

Improved

Stable

Degraded

Improved

Stable

Degraded

Degraded

Degraded

Degraded

Degraded

Degrradeded
Degraded

Degraded
Very high degradation Very high degradation Very high degradation b) CLDI

A

$\begin{array}{lll}0 & 3 & 6\end{array}$
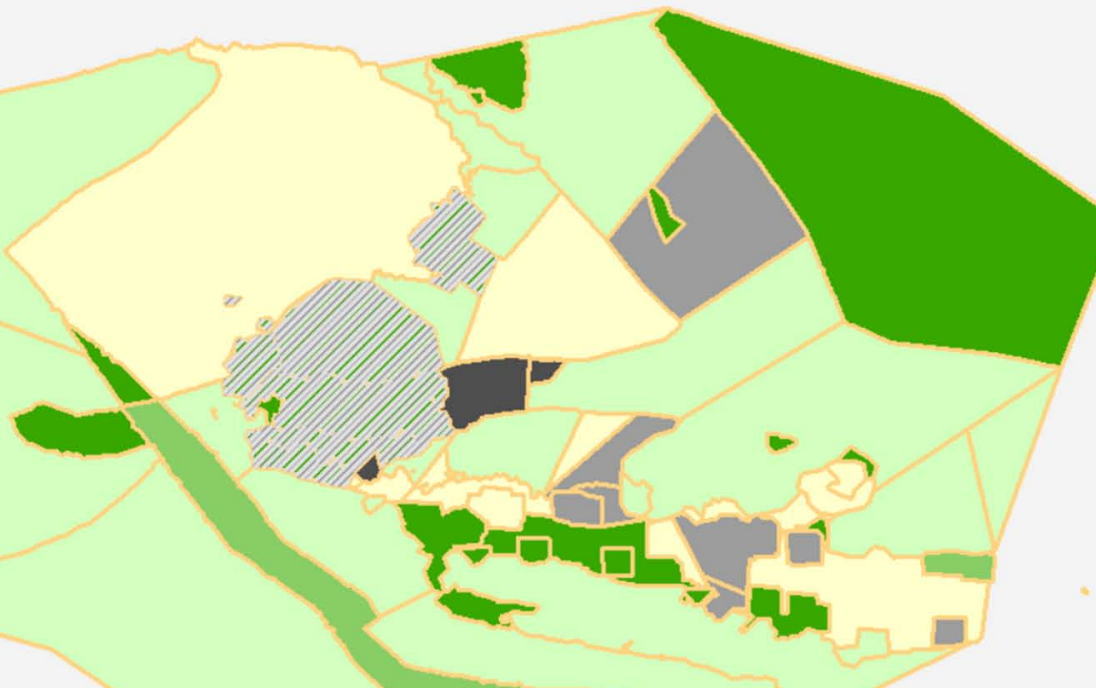

Kilometres

12. Settlement

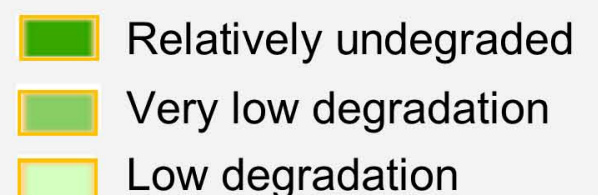

d)

100
90
80
70
60
50
40
30
20
10
0

CLDI

SDG 15.3.1 (NM)

SDG 15.3.1 (DD)
Medium degradation High degradation

Very high degradation

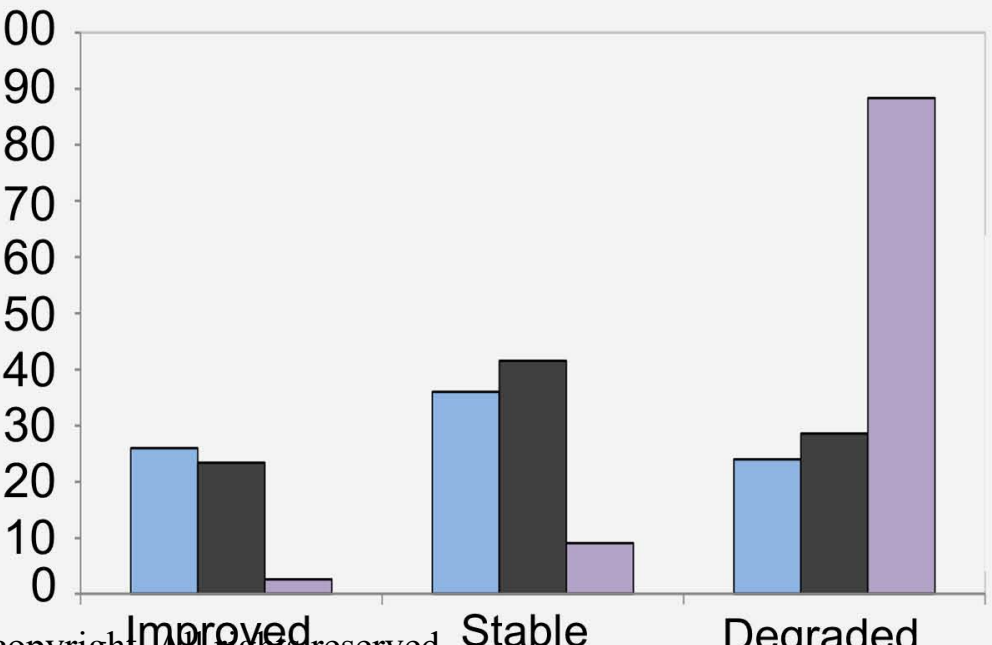

Degraded 